\title{
Incremental planning of the location of public health facilities in a rural region
}

\author{
Olayinka Waziri Otun \\ Department of Geography,Faculty of Social Sciences, Olabisi Onabanjo University Ago-Iwoye, Nigeria
}

Received: 2020-07-26 Accepted: 2021-01-05

Keywords:

Health care accessibility:

Inclusive development;

Incremental planning;

Location-Allocation models; Nigeria.

Correspondent email:

otunwo@yahoo.com

\begin{abstract}
Some people in rural areas are often excluded from using health facilities in developing nations due to political interference in facility location decision-making. Limited attention has been paid in the literature to promoting inclusiveness in public facilities usage in developing nations. Therefore, this study was designed to examine the access to Primary Health Centres (PHCs) in the Yewa region, Nigeria. Data on the 509 settlements and 91 PHCs in the Yewa region were obtained from government directories. The pmedian Location-Allocation model was used for data analyses. The study showed that the number of PHCs increased and access to them improved in the Yewa region between 1991 and 2019. It was also shown that inclusiveness in facilities could be promoted by optimally adding new PHCs. The study assessed the effectiveness of past locational decisions, similar to other studies in Bangladesh and India, and revealed that the military administration performed better than the civilian administration in facility location decisionmaking between 1991 and 2019. The study showed how new facilities could be optimally located to improve access and inclusiveness in public usage.
\end{abstract}

2021 by the authors. Licensee Indonesian Journal of Geography, Indone

incess article distributed under the terms and

Attribution(CC BY NC) licensehttps://creativecommons.org/licenses/by-nc/4.0\%.

\section{Introduction}

Primary health care facilities usually serve as the first line of service to meet people's primary health care needs (Novignon \& Novignon, 2017). However, these facilities are not usually adequate in low and middle-income countries (Hafidz et al., 2018), particularly the rural and marginal regions of such countries. Therefore, it is essential to understand how to efficiently plan for their provision (Alhassan et al., 2015). The inherent method of public facility provision in most countries is the incrementalist approach. With this approach, provision is made for facilities yearly, in the government budget, instead of implementing a comprehensive long-range plan. Interference by politicians in location decision-making, under the incrementalist approach, can result in facilities' poor location. Such poor location patterns can exclude some potential users from the facilities. However, adopting proper planning methods can improve inclusiveness in public facilities usage, thereby improving people's welfare. There is a gap in the literature on optimizing incremental facility location decision-making in developing nations. Locating new facilities will optimally improve access to such facilities and thereby ensure inclusiveness in public facilities usage. Therefore, this study will evaluate access to existing health facilities and compare civilian and military administrations' performance in incrementally locating public primary health facilities. It will also provide a method of optimally adding new facilities to existing ones to improve access and inclusiveness in health facilities usage within the Yewa region, Ogun state, Nigeria, between 1991 and 2019.
This section describes the conceptual basis for this work and reviews relevant literature in the planning and providing of public facilities. It examines the incrementalist approach to planning and how political interference in the incremental procedure can exclude prospective public facilities users, which is opposed to inclusive development. The section also looks at how Location-Allocation (L-A) models can be used as tools to plan facilities' location and improve access and inclusiveness in public facility usage. Also, Central Place Theory (CPT), which provides the L-A models' underlying principles, was examined.

Incremental planning is a piecemeal pragmatic approach to developing solutions to problems as they arise rather than planning for them in a comprehensive, overarching way as rational planning does (Anderson and Harbridge, 2010). In an attempt to produce a model to describe how satisfactory decisions are made in practice, Lindblom (1959) espoused the incrementalist model as an alternative planning decision theory to the rational model. He argued that rational or comprehensive planning was out of step with political realities. With the incrementalist planning model, alternatives are considered only marginally different from the status quo, and decisions are made quickly through limited alternatives, analyses, and evaluation (Cairney, 2012). The incrementalist model provides small, piecemeal solutions to often more extensive and more complex problems. Incremental planning is based on Herbert Simon's "principle of bounded rationality." The premise behind Simon's principle is that humans have a limited capacity to solve and 
understand problems compared to the vast and expansive list of current and future obstacles that are trying to be resolved (Brooks, 1998). Thus, they tend to settle for a satisfactory solution rather than an optimal solution. However, such a satisfactory solution might not be "good enough" for the purposes at hand, as proven in this study. In many parts of the world, governments often adopt an incrementalist planning model, whereby provision for facilities is based on resource allocation for the facility in the yearly budget, rather than on a long term plan. Despite the practical applicability of the incrementalist model, it has been criticized. Critics argue that the model is conservative (Atkinson, 2011). It emphasizes comparison with the past rather than having a wholesome radical change (Hayes, 2017).

In some cases, past decisions may not be right. If the incremental model is consequently applied, the error in earlier decisions will reverberate into future decisions. However, due to its short term outlook, it is more amenable to political interference. Political interference in facility location decision-making can lead to poor facility location and exclude some people from accessing such facilities. This is contrary to the goal of inclusive development, as discussed below.

Inclusive development refers to improving the distribution of amenities (health, education, infrastructure, etc.), intending to enable participation by all amenities (Sachs, 2004; Joshi, 2010). However, the emphasis in the literature on developmental studies is more on inclusive growth than inclusive development (Gupta et al., 2015). Inclusive growth emphasizes the economic aspect of development, while inclusive development has a broader scope as it emphasizes aspects of wellbeing. To buttress the broadness of inclusive development, Ranieri\& Ramos (2013) showed that inclusiveness requires addressing dimensions beyond what pertains to merely improving the poor's income condition. Emphasis on inclusive development could be traced partly to the failure of trickle-down theories that promote the concentration of resources at the core of the peripheries' detriment. Generally, "inclusive development is about countering exclusiveness" (Gupta et al., 2015). Difficulties in achieving sustainable development goals and concern for the poorest and most marginalized brought about the inclusive development concept (Gupta, \& Vegelin, 2016). One aspect of inclusive development literature is how social benefits can be redistributed to reduce marginalization, poverty, and improve access to basic public facilities (Lawson, 2010). Access to basic public facilities is fundamental to human wellbeing. A lack of access, especially by the poor in rural areas, will be inequity. This is opposed to the goal of inclusive development. Some scholars have argued for the adoption and implementation of good governance principles ( Sachs, 2004). For example, concerning the provision of public facilities, a nation's constitution can be enhanced to protect against discrimination, to promote access to basic public facilities as a human right, encourage stakeholders' participation in public facility location decision process, resolve the conflict between efficiency and equity objectives in public facility location decision process, etc. The suggestion for good governance principles as a driver of inclusiveness is fundamental, as one key driver of exclusion and inequity is unequal access to basic facilities like education, health, good water, sanitation, etc. The concept of public service ensures that basic facilities are provided from the commonwealth either free or subsidized to everybody irrespective of income. The concept of public service is discussed below.

Public service is the service received from that portion of the government's gross national product at all levels (Spicker, 2009). The term is associated with a social consensus that certain services should be available to all, regardless of income (Wikipedia, 2019). The objectives in the provision of public services are to ensure equal accessibility to the services and maximize societal benefit or welfare while minimizing cost and using resources in the most rational way possible. A key objective in service provision and planning is accessibility, as discussed below.

Accessibility, as defined by Halden et al. (2005) is "the ease with which a given destination can be reached from an origin or set of origins" This is usually referred to as facility accessibility. According to Ayeni \& Rushton (1986), "the issue of accessibility as a concept is the most commonly articulated and the least understood in locational studies". Accessibility can be classified based on such issues as availability, accessibility, accommodation, affordability, and acceptability (Abdulkader, 2018). Three components that are considered in studies on accessibility are: (i) the spatial distribution and characteristics of the health services; (ii) the transport network linking users and service providers and (iii) the socio-economic characteristics of users of health services. (Higgs, 2004). The International Conference on Primary Health Care met in Alma-Ata in 1978 and declared, among others, that "health is a fundamental human right" (WHO, 1978). However, primary health care services are not always readily accessible, affecting the most vulnerable people in society (Richard et al., 2016). As suggested by Rushton (1984), "Improved geographical accessibility to basic services for rural populations should be a goal of most governments in developing countries". Thus access is a key concept in service planning (O'Donnell et al., 2016). To put the concept of accessibility into operation, Location-Allocation models are often used, as discussed below.

Location-Allocation (L-A) models have been developed and used for putting facility location objectives into operation. L-A methods aim to distribute facilities in a "Pareto-optimal" way such that a user's access cannot be made better without making another user's access worse. The Location Allocation problem is concerned with the siting of one or more facilities (the location problem) and the allocation of consumers to these facilities in a way that optimizes certain objectives such as: minimizing transportation costs/ distance traveled and maximizing population covered. Most Location-Allocation problems take three spatial forms: (i) the general problem, which refers to a situation where no facility exists in the area in question, and the facilities are to be allocated freely, (ii) incremental facility problem, which refers to a situation where some facilities of the type being located already exist in the area, and these locations are taken into account when locating new facilities and (iii) reorganized problem, which refers to a system where the spatial system of facilities is reorganized by closing down the poorly located facilities and allowing new ones that are appropriately located to be established. The Central Place Theory (CPT), outlined below, provides the underlying principles on which the Location-Allocation methods are based. 
The Central Place Theory (CPT) explains the size, number, and spacing of central places (facilities) supplying goods/services to the surrounding population (Briney, 2020). The two significant principles underlying CPT are the range and the threshold of a good or service. The range of a good or service is the distance from the supplier (at which the consumer becomes unwilling to travel to purchase the good or service). The threshold is the minimum demand or size of the market necessary to produce a good or service (Daniels, 2017). The range and threshold concepts of the CPT are relevant to the planning location of facilities.

Following the reviewed literature's assertion, decisionmakers in public facilities provision tend to settle for a satisfactory solution rather than an optimal solution. Some studies have been carried out to measure the effectiveness of past locational decisions. These studies include the study by Rahman \& Smith (1996) in Tangail Thana in Bangladesh, Fisher \& Rushton (1979) study in Junagadh, India. Also, Hodgson \& Valadares (1983) study in Goa, India. These studies used the p-median method of Location-Allocation models to assess the existing pattern of public health facilities location and evaluate past location decisions' effectiveness. However, none of these studies focused on how new facilities can be optimally added to existing facilities under an incrementalist decision-making framework. This is the focus of this study. This study aims to assess the performance of two types of administrations in incremental location decision -making and provide a method to add new facilities to existing ones optimally.

\section{Method}

The methodology to achieve this study's objectives involves capturing and storing geo-coded data on settlements and health facilities' location, using the Geographic Information System (GIS). Location-Allocation methods were used to generate and assess health facility location plans.

\section{The study area}

Yewa region in Ogun State, Nigeria, is the study area for this work, and it is predominantly a rural region. Yewa region is located at the border fringe of Ogun state (see Figure 1), and it is comparatively disadvantaged in the state concerning health facilities provision. For example, as of $2009,29.7 \%$ of all the Ogun State population could be found in the Yewa region, but only $24.1 \%$ of all public health facilities in Ogun State were sited in the region (Otun, 2016). The study area lies between Latitudes $6^{0} 26^{\prime}$ and $7^{0} 56^{\prime}$ north of the Equator; and Longitudes $2^{0} 41^{\prime}$ and $3^{0} 27^{\prime}$ east of the Greenwich Meridian. Ogun state lies in the south-western part of Nigeria, and the Yewa region lies at the western borderline of Ogun state. The region comprises five local government areas. There are 91 publicly owned Primary Health Centres (PHCs) to serve 509 settlements in the region.

\section{Data for the study}

A database developed for the study consists of geographic coordinates to describe locations of Primary Health Centres (PHCs) in the Yewa region in 1991(census year), 1999(end of military rule), and 2019(current date). Coordinates and population of all 509 settlements in the region and the transport networks were part of the database. The coordinates of the PHCs and settlements' locations were generated from digitized topographic map sheets (scale $1: 50,000)$ covering the study area. The settlements' population size was collected from the National Population Directory (Federal Government of Nigeria, 2007) and projected to 2019. The transport networks consist of the main roads, secondary roads, and footpaths. The transport network pattern was generated by digitizing the roads and footpaths from the topographic map sheets and updated through field visits. The settlements, PHCs, and transport networks were created as map layers or themes in the database. They are the primary data used in the Location-Allocation analysis.

\section{Techniques of analysis}

The methods of analysis used in this study are described in this section. The Location-Allocation (L-A) analyses in this study were carried out using the L-A module of Network Analyst in ArcGIS $v$ 10.5. The solution methods of LocationAllocation solver generates an origin-destination matrix of shortest-path costs between all the facilities and demand point locations along with the network. Heuristics are used to solve different problem types by the Location-Allocation solver. The problem type in this study is minimized weighted impedance. The ArcGIS Location-Allocation solver for minimized weighted impedance is based on the p-median problem. The p-median framework has provided a framework for optimizing public facilities' location (Segura et al., 2016). Optimization in the geographical space involves solving a mathematical problem to find optimal location patterns by allocating demand points to their closest service centers. The distance traveled from all the demand points to all the service centers is minimum. The p-median model is applicable in operation, the concept of efficiency (minimizing travel distance) in public facility location planning, and the mathematical description.

The p-median problem is a Location-Allocation problem that considers the average distance between demand points and facility. The model is used to determine the best or optimal location to place a limited number of facilities. The model has been enhanced and applied to a wide range of location problems (Ndiaye, 2012). The p-median model for finding an efficient set of flow between demand points and service centers is specified thus (Daskin, 2013):

Mathematical description of the p-median model

\section{Minimize $\quad F_{1}=\sum_{i \in I} \sum_{j \in J} h_{i} d_{i j} y_{i j}$}

Subject to:

$$
\text { ( the objective function) }
$$

$\sum_{j \in J} x_{j}=p$

$\sum_{f \in J} y_{i j}=1 \forall i \in I$

$y_{i j}-x_{j} \leq 0 \forall i \in I, j \in J$

$x_{j} \in\{0,1\} \forall j \in J$

$y_{i j} \in\{0,1\} \forall i \in I, j \in J$

The objective function minimizes the demand-weighted total cost. where: 
$\mathrm{I}=$ the set of demand nodes indexed by $\mathbf{i}$

$\mathrm{J} \quad=$ the set of facility locations, indexed by $\mathbf{j}$

Dij $=$ distance between demand node $\mathbf{i}$ and facility site $\mathbf{j}$

hi $=$ demand at node $\mathbf{i}$

$\mathrm{p}=$ the number of facilities to locate

$$
\begin{aligned}
& x_{j}=\left\{\begin{array}{c}
1 \text { ifwe locate at site } j \\
0 \text { ifnot }
\end{array}\right. \\
& y_{i j}=\left\{\begin{array}{c}
1 \text { ifdemand node } i \text { is assigned to a facility at node } j \\
0 \text { ifnot }
\end{array}\right.
\end{aligned}
$$

The objective function (1) minimizes the demandweighted total cost traveled. Constraint set (2) stipulates that $\mathrm{p}$ facilities are to be located. Constraint set (3) requires that each demand node be assigned to exactly one facility. Constraint set (4) restricts demand node assignments to open facilities only. Constraint set (5) established the siting decision variable as binary. Constraint set (6) requires the demand at a node to be assigned to one facility only. For more detail about the p-median problem, see Carling \& Hakansson (2013).

\section{Results and Discussion}

Most developing nations do not have a comprehensive framework for planning public facilities; instead, the government adopts an incrementalist planning model whereby new facilities are added to the existing ones, according to resources allocated for the facility in the yearly budget. The concern is how good or efficient are the locations of facilities added under the incremental decision-making model and the extent to which they improve the inclusiveness of potential users. This study compared the Average Travel Distance (ATD) in the existing facility pattern with ATD in a modeled optimal pattern to assess the government's location decision-making. This study's concern is how to improve location and access to public health facilities under the incremental decision-making model. Such facilities are part of public service, and the concept of public service is that it is to be provided to all, regardless of income. The primary factor that can hinder consumption is the separating distance between a consumer and the facility. Thus, this study's attention is on the effect of physical distance as a measure and determinant of access to public health facilities. The ATD from the settlements to the facilities was used as a measure of physical access. The pmedian location-allocation model in ArcGIS $v 10.5$ was used to compute the ATD, where all settlements are allocated to their nearest facility. The model was also used to find the optimal location pattern for facilities. The statistics generated from the application of the p-median model are shown in Table 1. Graphical illustrations of output from the p-median model application were also generated.

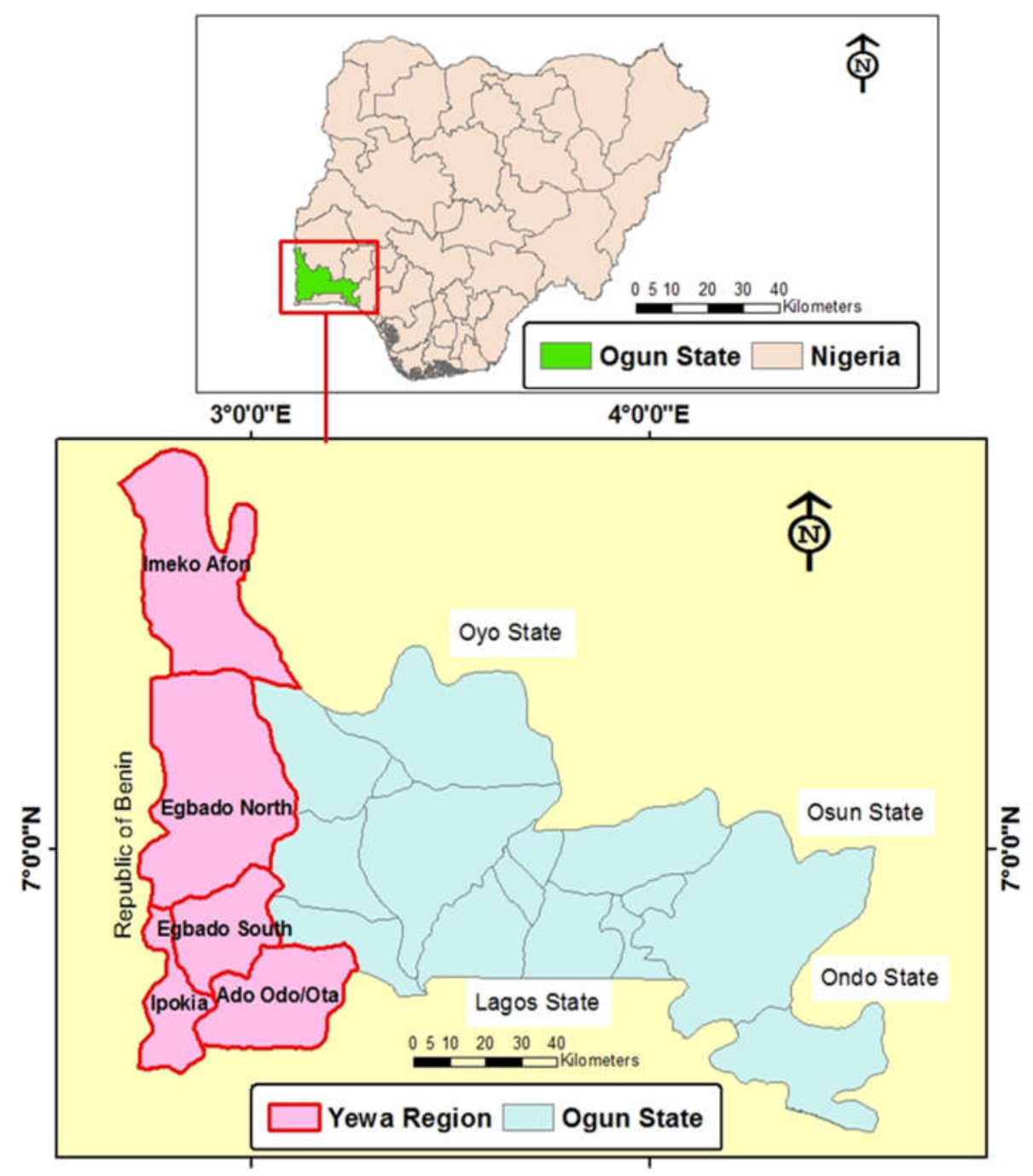

Figure 1. Ogun state and Yewa region, the study area 
Location decision-making of the government in 1991 was evaluated by comparing the average travel distance in the existing pattern of 64 PHCs $(6.01 \mathrm{~km})$ with the modeled pattern. The locations of the 64 existing PHCs could be optimally reorganized (by closing some facilities and opening new ones in better locations) to reduce the average travel distance to $4.43 \mathrm{~km}$, thereby improving access to the PHCs. Comparing the ATDs in the existing and modeled facility pattern showed that the government's location pattern's efficiency in 1991 was $73.71 \%$ (see Table 1 ).

The Location decision making of military and civilian governments of Nigeria between 1991 and 2019 was compared. The rationale for comparing the two types of administrations is based on the common belief that political interference in facility location decision is more pronounced during civilian rule than during military rule. Political interference in decision-making, rather than rational justification, can skew and poor facilities' location and, consequently, reduced access and inclusiveness in facilities usage. Between 1991 and 1999, the military administration added nine Primary Health Centers (PHCs), thereby added were optimally chosen. See figure 2 a for the existing facility locations in 2019, and figure $2 \mathrm{~b}$ shows the 18 optimally chosen locations. The difference between the two figures is that in figure $2 \mathrm{~b}$ all the 73 PHCs in 1999 were retained, while some of the 18 facility locations added by the civilian administration, after 1999 were retained, and some new optimal locations were added. The optimal pattern yields an ATD of $3.39 \mathrm{~km}$. Thus the modeled pattern (ATD $=3.39 \mathrm{~km}$ ) provides better access and inclusiveness in facility usage than the civilian administration's location pattern $($ ATD $=4.62 \mathrm{~km})$. The efficiency in location decision-making during the civilian administration was $71.31 \%$ (see Table 1 )

The difference between the ATD in the existing and the modeled location patterns of facilities is shown in figure 3. The figure shows that ATD to facilities (a measure of access to facilities) had declined, and inclusiveness in facilities usage improved between 1991 and 2019. However, access and inclusiveness in facilities usage can be improved using the incrementalist decision-making model by optimally adding new facilities.

Locational efficiency (determined by comparing ATD in

Table 1. Actual and modeled average distance from primary health centers between 1991 and 2019

\begin{tabular}{ccccc}
\hline Year & Number of facilities & $\begin{array}{c}\text { Actual pattern: } \\
\text { average travel distance }(\mathrm{km})\end{array}$ & $\begin{array}{c}\text { Modeled pattern: } \\
\text { average travel distance }(\mathrm{km})\end{array}$ & Efficiency level \\
\hline 1991 & 64 & 6.01 & 4.43 & 73.71 \\
1999 & 73 & 5.59 & 4.08 & 72.99 \\
2019 & 91 & 4.62 & 3.29 & 71.31 \\
\hline
\end{tabular}

Source: Generated using the Location-Allocation procedure of ArcGIS v.10.5

increasing the number of PHCs from 64 in 1991 to 73 in 1999 (see table 1). The Average Travel Distance (ATD) decreased from $6.01 \mathrm{~km}$ (1991) to $5.59 \mathrm{~km}$ (1999). Thus, access and inclusiveness in facility usage improved during the period. However, finding optimal locations for the newly added nine PHCs, access and inclusiveness in usage can be further improved. Location decision-making of the military administration is assessed by comparing the reduction in ATD achieved by the newly added nine PHCs between 1991 and 1999, with the reduction in ATD to be achieved by modeled pattern. To evaluate objectively, it is the location of the nine newly-created PHCs that should be considered. However, the nine PHCs cannot be evaluated in isolation, as all settlements are allocated to all PHCs simultaneously; thus, the modeling approach adopted is that the 64 existing PHCs in 1991 (at the commencement of military administration) were fixed in the modeling process, while the locations of the nine newly added PHCs were optimally chosen. The optimal facility pattern yields an ATD of $4.08 \mathrm{~km}$, which gives better access and inclusiveness in facility usage. Comparing ATD achieved in the military's location pattern with the ATD in the modeled pattern in 1999, it yields an efficiency of $72.99 \%$ (see table1). Thus, the efficiency in location decision-making during the military administration was $72.99 \%$.

During the civilian rule (1999 to 2019), 18 PHCs were added to the existing 73 PHCs. Here ATD decreased from $5.59 \mathrm{~km}$ in 1999 to $4.62 \mathrm{~km}$ in 2019 . The modeled optimal pattern was generated by fixing the locations of the existing 73 PHCs in 1999, and the locations of the 18 PHCs to be

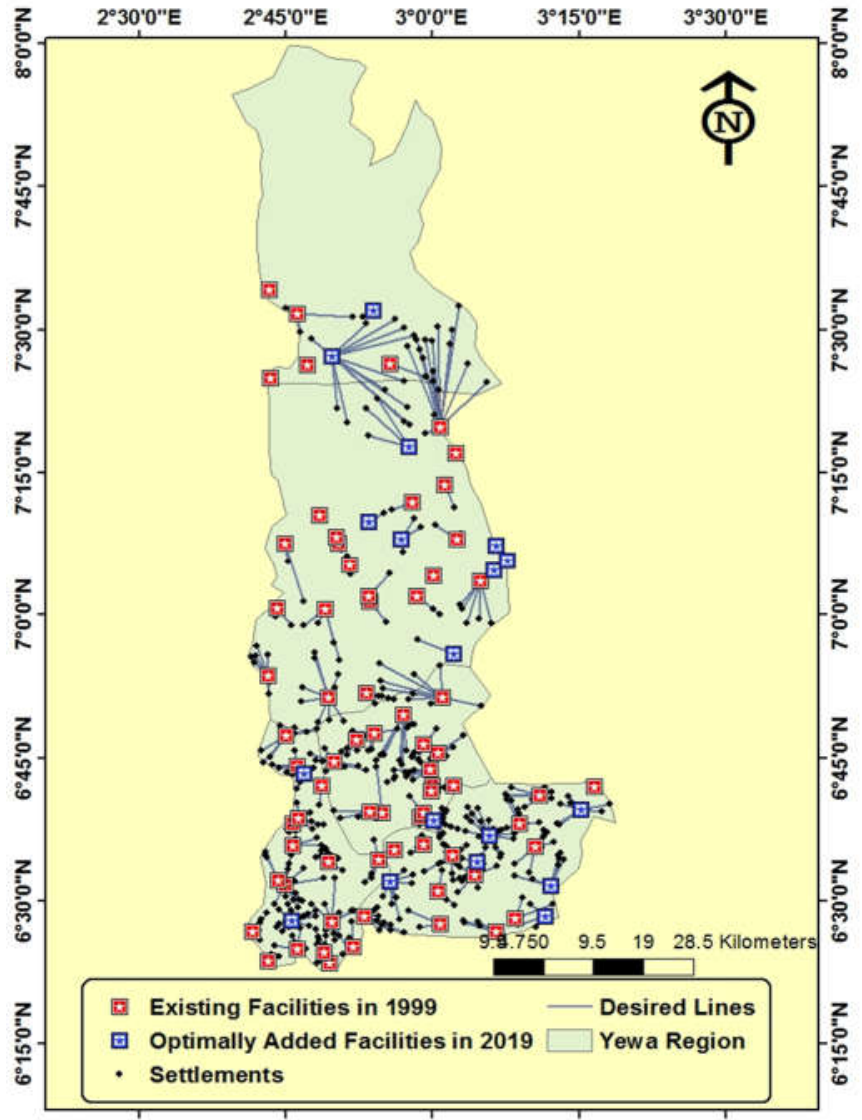

Figure 2b. Optimal Locations of Facilities in 2019 


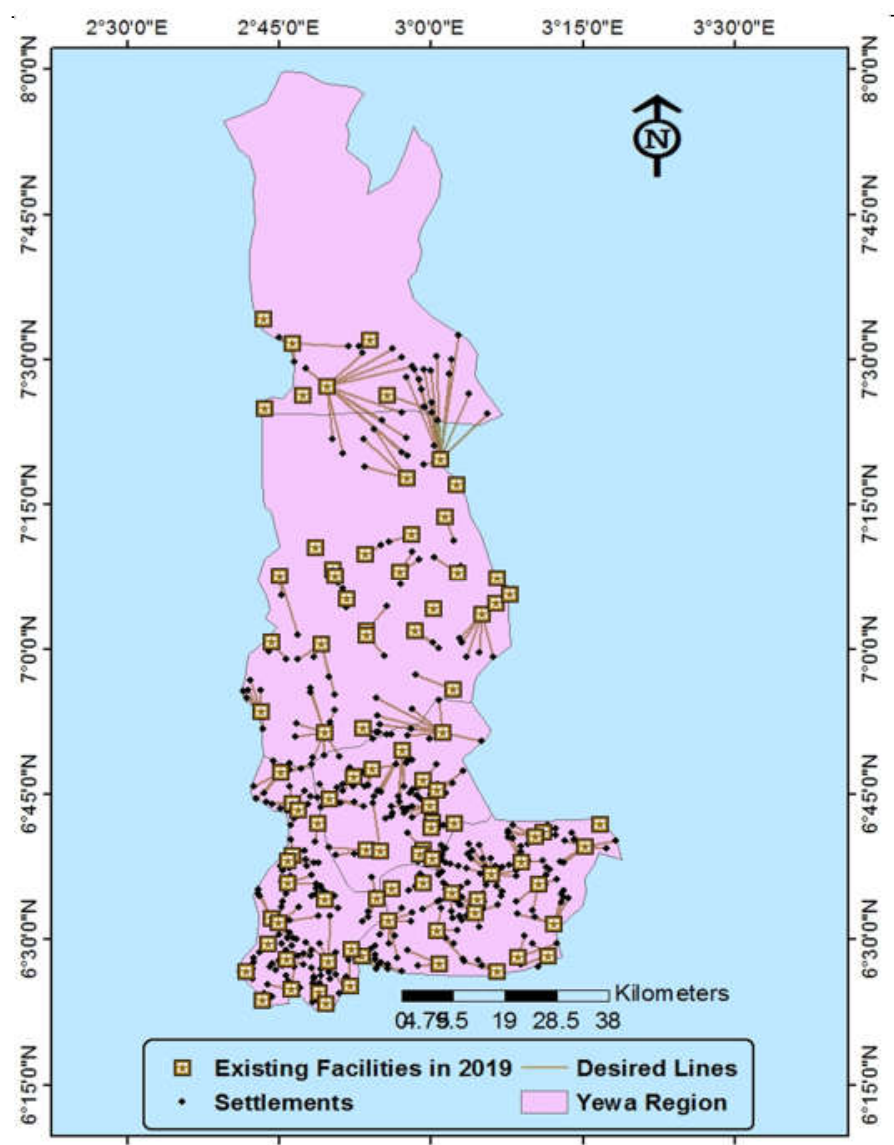

Figure 2a. Existing Locations of Facilities in 2019

the existing pattern of facilities with the modeled pattern of facilities) of health facilities during the civilian government (1999 to 2019) was $71.31 \%$, while it was $72.99 \%$. During the military rule (1991 to 1999). Thus, the military administration performed better in locating facilities than the civilian administration. This is probably due to more interference in politicians' public facility location decision process than by the military. In the absence of a comprehensive plan for the location of health facilities, it has been shown that the location of new facilities to be added to existing ones can be optimally planned to improve overall access and inclusiveness in facility usage. As good as this approach might look, objectivity in public facilities' planning locations can be constrained by political interference. Public facilities are at times located based on a promise to a community during political campaigns, and the location of such a promised facility might run contrary to the overall objective of health care service delivery.

\section{Discussion}

Accessibility is a key concept in health service provision and planning. There are different dimensions to the meaning of health care accessibility. Aday \&Anderson (1974) consider some of these dimensions as financial, informational, and behavioral in addition to geographical or spatial accessibility. The focus of this study is geographical or spatial accessibility. This has been determined as the separating distance between the users and service providers. The distance can be measured in monetary cost, time spent, or actual physical distance. Throughout this study, the emphasis has been on the physical distance that separates the users and service providers, along with the existing road network.

Location-Allocation models, particularly the p-median method, have been used in developing countries to improve health facilities access. The methods have been used to assess existing location patterns, find the best location for health facilities, and evaluate past location decisions (Rahman \& Smith, 2000). The p-median model has been used to assess existing facilities' performance in the study by Ayeni \& Rushton (1986) in Ogun Central Senatorial District, Ogun State, Nigeria. It was found that the average travel distance to 53 maternity and child welfare centers was $2.73 \mathrm{~km}$. Also, Owoola (2002) used the p-median method to assess health dispensaries' location in the Oke Ogun area of Oyo State, Nigeria, and found the average distance from the settlements to the dispensaries was $6.69 \mathrm{~km}$. This study also used the pmedian method and found the average distance to primary health centers in the Yewa region, Ogun state, Nigeria, to be $6.01 \mathrm{~km}$ in 1991, which declined to $4.62 \mathrm{~km}$ (in 2019). These studies showed that there could be disparities in access to health facilities in different regions of a country. The government needs to address the issue of disparity in access to health facilities. It was declared at the Alma-Ata International Conference on health in 1978 that "the existing gross inequality in people's health status is unacceptable" (WHO, 1978). However, international standards recommend that primary healthcare facilities be located within a $5 \mathrm{~km}$ distance of users (Kemboi \& Waithaka, 2013).

The p-median can also be used to find optimal locations for new facilities. This was demonstrated in the study by Mehretu (1983) in Burkina Faso. He used the p-median method to locate rural health clinics, where every rural household had access to health care within a maximum distance of $5 \mathrm{~km}$.

There are previous studies that have been carried out to measure the effectiveness of past locational decisions. These include the study by Rahman \& Smith (1996), who assessed the efficiency of the sites for health and family welfare centers in Tangail Thana in Bangladesh, and found out that the average travel distance to the existing facilities was $3.1 \mathrm{~km}$ while the application of the p-median method yielded an optimal distance of $1.9 \mathrm{~km}$. Fisher \& Rushton (1979) used the p-median method and found out in their study in Junagadh, India, that the pattern of existing health facilities and some other services was 1.22 times inefficient than the optimal system. Also, Hodgson \& Valadares (1983) study the spatial inefficiency of Goa, India's existing health system, and found it 1.56 times. The measure of efficiency was carried out in this study, using the p-median method, and the average distance of the existing pattern of health facilities was compared with an optimal pattern. It was shown that the efficiency of the existing pattern of health facilities was $73.7 \%$ in 1991 , and it declined to $71.3 \%$ in 2019 . This study also used the p-median method to assess the existing pattern of public health facilities location and evaluate past locations' effectiveness by different administrations. The study demonstrated, in addition to what previous studies have done, how new facilities can be optimally added to existing facilities under an incrementalist decision-making framework. For example, as shown in this study, the military administration added nine Primary Health Centres (PHCs) between 1991 and 1999. The nine PHCs led to a decreased average distance from $6.01 \mathrm{~km}$ to $5.59 \mathrm{~km}$. However, the Location-Allocation model was used to choose optimal locations for the nine PHCs such that the average distance decreased to $4.08 \mathrm{~km}$. 


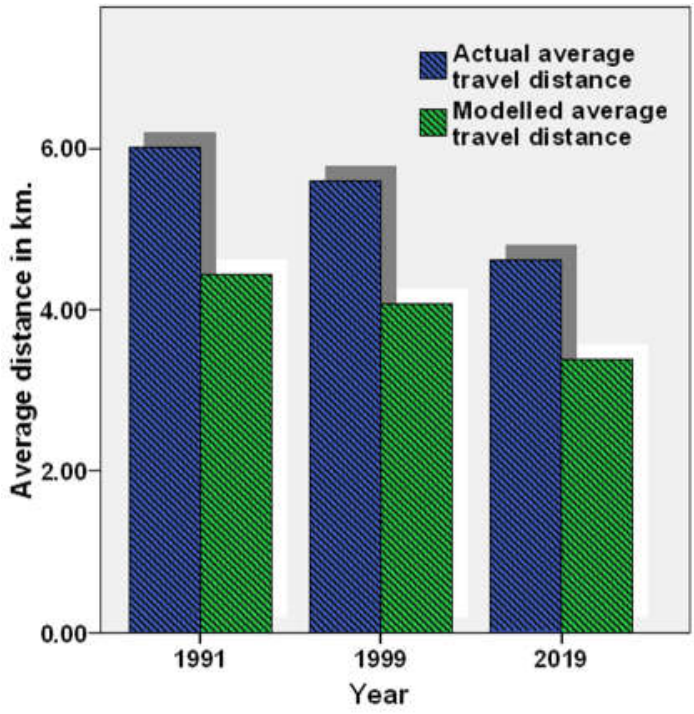

Figure 3. Average travel distance in the existing pattern and modeled pattern of facilities

Recently, travel time data is increasingly available in some countries, and this is having an effect on studies on access to health facilities. Some recent studies used drive-time analysis to determine access to health facilities by specifying minimum and maximum standard distances required to reach health facilities in minutes (Bagheri, et al. 2005; Nichols, et. al. 2014; Abdulkader, 2018 \& Abdelkarim, 2019). Where travel time data is available, they give a more realistic measure of access to public facilities because a nasty but short distance road can hinder access to a health facility than an excellent but long-distance road.

\section{Conclusion}

The study showed that the number of PHCs increased, and access and inclusiveness in usage improved in the Yewa region of Ogun state, Nigeria, between 1991 and 2019. However, results from model application, under incrementalist decision-making framework, provided better access and inclusiveness in facility usage, thus suggesting that decision-making under incrementalist framework can produce public facility location decisions that will improve access inclusiveness in usage in developing nations. To improve access, location models can be employed to decide the optimal location of additional facilities approved in yearly budgets under an incremental decision-making framework.

This study argues that present planning can be optimized to reduce the total errors irrespective of the errors in past location decisions. Political influence in public facility location decision-making should be minimized to maximize benefits from allotted facility provision resources. This study has shown how to develop appropriate tools for assessing and identifying locations that will yield improved public facilities access. It is advisable for planners in developing countries to adopt these techniques.

\section{References}

Abdelkarim, A. (2019). Integration of location-allocation and accessibility models in GIS to improve urban planning for health services in Al-Madinah Al-Munawwarah, Saudi Arabia. Journal of Geographic Information System, 11, 633-662. doi: 10.4236/ jgis.2019.116039.

Abdulkader, M. (2018). Using GIS for Determining Variations in
Health Access in Jeddah City, Saudi Arabia. ISPRS International Journal of Geo-Information, 7, 254 https://doi.org/10.3390/ ijgi7070254

Aday, L.A., Anderson, R. (1974). A framework for the study of access to medical care. Health Serv. Res. 9.

Alhassan, R.K., Nketiah-Amponsah, E., Akazili, J., Spieker, N., Arhinful, D.K., Rinke de Wit T.F.(2015). Efficiency of private and public primary health facilities accredited by the National Health Insurance Authority in Ghana. Cost Eff. Resource Allocation, 13(1) (no pagination). http://dx.doi.org/10.1186/ s12962-015-0050-z.

Anderson, S. , Harbridge, L. (2010). Incrementalism in appropriations: Small aggregation, big changes. Public Administration Review. 70 (3): 464-474. doi:10.1111/j.15406210.2010 .02160

Atkinson, M. (2011). Lindblom's lament: Incrementalism and the persistent pull of the status quo. Policy and Society, 30(1), 9-18. Retrieved from: https://doi.org/10.1016/j.polsoc.2010.12.002

Ayeni, B. \& Rushton, G. (1986). Distributional equity and efficiency in the locational analysis of public facilities: a case study. The Nigerian Geographical Journal, 28-29(1-2): 115-135.

Bagheri, N. Benwell, G. \& Holt, A. (2005). Measuring spatial accessibility to primary health care. In Proceedings of the SIRC 2005-The 17th Annual Colloquium of the Spatial Information Research Centre University of Otago, Dunedin, New Zealand, 24 -25 November 2005

Briney, A. (January,2020) An overview of Christaller's central place theory. Retrieved from: www.thoughtco.com/central-placetheory-1435773

Brooks, T. A. (1998). Information seeking in context. Journal of the American Society for Information Science, 49(6). https:// doi.org/10.1002/(SICI)1097-4571(19980501)49:6<573

Cairney, P. (2012). Understanding public policy. Basingstoke: Palgrave Macmillan.

Carling, K., Hakansson, J. (2013). A compelling argument for the gravity p-median model:short communication. Eur. J. Oper. Res. 226, 658-660.

Daniels, P.W. (2017). Central place theory. New Jersey, USA: John Wiley \& Sons Ltd. https://doi.org/10.10002/9781118786352. wbiego 0747

Daskin, M.S. (2013). Network and discrete location: Models, Algorithms and Applications. New York, USA: Wiley and Sons, Inc., ISBN: 0-471-01897-X.

Federal Government of Nigeria (2007) Legal notice and publication of details of the breakdown of the national and state provisional totals of 2006 census. Federal Government of Nigeria Official Gazette: No. 24, Vol. 94.

Fisher, H. B. , Rushton, G. (1979). Spatial efficiency of service locations and the regional development process papers, Regional Science Association, 42 .

Gupta, J., Cornelissen, V. , Ros-Tonen, M.A.F. (2015).Inclusive development in P. Pattberg and F. Zelli (Eds.) Encylopedia of global environmental governance and politics. Cheltenham, U.K: Edward Elgar.

Gupta, J. , Vegelin, C. (2016). Sustainable development goals and inclusive development, International Environmental Agreements: Politics, Law and Economics, Springer, 16(3), 433448.

Hafidz, F., Ensor, T., Tubeuf, S. (2018).Efficiency measurement in health facilities: asystematic review in low- and middle-income countries. Applied Health Economics and Health Policy. 16, 465 -480 .

Halden, D., Jones, P., Wixey, S. (2005). Measuring accessbility as experienced by different socially disadvantaged groups. Working Paper 3, University of West Minster: Transport Studies Group.

Hayes, M. (2017). Incrementalism and public policy-making. Oxford Research Encyclopedia of Politics. Retrieved from: http:// politics.oxfordre.com/view/10.1093acrefore/978019 0228637.001.0001/acrefore-97801902286 37-e-133.

Higgs, G. A. (2004). Literature review of the use of GIS-based 
measures of access to health care services. Health Serv. Outcomes Res. Methodol. 5.

Hodgson, M. J. , Valadares, C. (1983). The spatial efficiency of health centres in Salcette, Goa National Association of Geographers of India, Annals, 3.

Joshi, G.S. (2010). Infrastructure development strategies for inclusive growth: India's eleventh plan. Leadership and Management in Engineering 10(2). 65-72. Doi: 10.1061/(ASCE) LM.1943-5630.0000057.

Kemboi, T.K. , Waithaka, E.H. (2013). GIS location-allocation model in improving accessibility to health care facilities: A case study of Mt. Elgon Sub-County. International Journal of Science and Research (IJSR) ISSN: 2319-7064

Lawson, V. (2010). Reshaping economic geography? Producing spaces of inclusive development. Economic Geography, 86(4).

Lindblom, C.E. (1959). The science of muddling through. Public Administration Review 19.

Mehretu, A. (1985). A spatial Framework for redressing disparities in rural service delivery systems, Tijdschrift voor Economische en Sociale Geogra, 76.

Ndiaye, F, Ndiaye, B, Mbaye, I. (2012). Application of the p-median problem in school allocation. American Journal of Operations Research, 2(2):253-259. doi: 10.4236/ajor.2012.22030

Nichols, E.N., Bradley, D.L., Zhang, X., Faruque, F., Duhé, R.J. (2014). The geographic distribution of mammography resources in Mississippi. Online J. Public Health Inform , 5, 226

Novignon, J. , Nonvignon, J. (2017).Improving primary health care facility performance in Ghana: efficiency analysis and fiscal space implications. BMC Health Services Research, 17(399).

O'Donnell, P., Tierney, E., O'Carroll, A., Nurse, D. \& MacFarlane, A. (2016). Exploring levers and barriers to accessing primary care for marginalised groups and identifying their priorities for primary care provision: a participatory learning and action research study. International Journal for Equity in Health 15:197 DOI 10.1186/

Otun, W.O. (2016). A spatial decision support system for special health facility location planning in developing regions. Ethiopian Journal of Environmental Studies and Management 9 (1).829-840.Doi:http://dx.doi.org/10.4314/ejesm.v9il.3S.

Owoola, M.A. (2002). Between policy and practice decision support system-based assessment of facility location planning in Nigeria. Proceedings of a symposium on geospatial theory, processing and applications, Ottawa, 2002.

Rahman, S. , Smith, D.K. (1996). The efficiency of inefficiency: The deployment of health facilities in rural Bangladesh, in: M. Alauddin, S. Hasan (Eds.), Bangladesh: Economy, People, and the Environment. Brisbane: Department of Economics, University of Queensland.

Rahman, S., Smith, D. K. (2000). Use of location-allocation models in health service development planning in developing nations. European Journal of Operational Research 123: 437-452.

Ranieri, R. , Ramos, R. (2013). Inclusive growth: Building up a concept. No. 4 Working Papers from International Policy Centre for Inclusive Growth. https://EconPapers.repec.org/ RePEc:wpaper:104.

Richard, L., Furler, J., Densley, K., Haggerty, J., Russell, G., Levesque, J., \& Gunn, J.( 2016). Equity of access to primary healthcare for vulnerable populations: the IMPACT international online survey of innovations. International Journal for Equity in Health 15:64 DOI 10.1186/s12939-016-0351-7.

Rushton, G. (1984) Use of location-allocation models for improving the geographical accessibility of rural services in developing countries. International Regional Science Review. https:// doi.org/10.1177/016001768400900303

Sachs, I. (2004). Inclusive development strategy in an era of globalization, Working Paper No. 35, Policy Integration Development, World Commission on the Social Dimension of Globalisation, Geneva: International Labour Office.

Segura, E., Carmona-Benitez, R.B., Lozanoa, A. (2016). Implications of the assumptions on which the p-median problem are based when distribution network design. World Conference on Transport Research - WCTR 2016 Shanghai, 1015 July 2016.

Spicker, P. (2009). The nature of a public service. International Journal of Public Administration. 32(11): 970-991. DOI: 10.1080/01900690903050927

WHO (1978). Declaration of Alma-Ata. International Conference on Primary Health Care, Alma-Ata, USSR, 6-12 September, 1978. http://who.int/publications/almaata_declaration_en.pdf.

Wikipedia (2019). Public service. Wikipedia, the Free Encyclopedia. Retrieved from: https://en.wikipedia.org/wiki/ Public_service. 